\title{
Horseradish Tolerance to Internal Root Discoloration
}

ISSN: 2637-7659

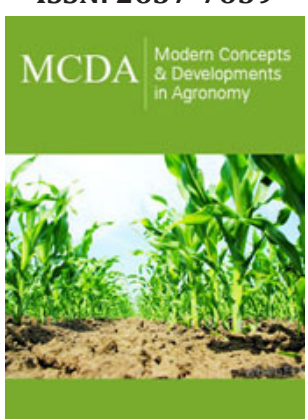

*Corresponding author: S Alan Walters, 1205 Lincoln Drive, Ag. Bldg. Rm 176, Department of Plant, Soil, and Agricultural Systems, Southern Illinois University, Carbondale IL, 62901, USA

Submission: 眥 November 06, 2019

Published: 眥November 13, 2019

Volume 5 - Issue 3

How to cite this article: S Alan Walters. Horseradish Tolerance to Internal Root Discoloration. Mod Concep Dev Agrono.5(3). MCDA.000612.2019. DOI: 10.31031/MCDA.2019.05.000612

Copyright@ S Alan Walters, This article is distributed under the terms of the Creative Commons Attribution 4.0 International License, which permits unrestricted use and redistribution provided that the original author and source are credited.

\section{S Alan Walters*}

Department of Plant, Soil, and Agricultural Systems, Southern Illinois University, USA

\begin{abstract}
Horseradish internal root discoloration (IRD) is a disease complex caused by several different soil-borne fungal pathogens and is the most important disease problem that affects horseradish worldwide, since it directly influences root marketability. Horseradish growers in North America have experienced yield losses up to $100 \%$ due to this disease complex. In Illinois, USA, horseradish is a major specialty crop that is grown in the southwestern part of the state near St. Louis, Missouri, and this region is considered the most concentrated horseradish production region in the world. Both Southern Illinois University-Carbondale and University of Illinois-Champaign have worked together during the last 20 years toward the development of improved horseradish varieties with IRD tolerance. The purpose of this study was twofold, first to evaluate current commercially grown horseradish clones for their tolerance to IRD under field conditions, and then to determine the suitability of clones found most tolerant for developing new improved cultivars with IRD tolerance. Most horseradish clones evaluated in IRD infested fields near Collinsville, Illinois, were highly susceptible, with only $15 \mathrm{~K}$ having consistent field tolerance. This clone has previously been observed under commercial field conditions by the author and several other sources to have some tolerance to IRD. Other horseradish clones that may have some potential IRD tolerance under field conditions were 315,7586 , and 9705 , based on the IRD incidence and/or IRD symptom severity that developed in the roots based on this study. Two horseradish clones $115 \mathrm{~K}$ and 315 ) were shown to be highly effective as parents for developing new cultivars having IRD tolerance. Breeding for tolerance to this disease complex has been the major focus in new horseradish cultivar development in Illinois, USA for the last several decades, which have included using $15 \mathrm{~K}$ and 315 as parents to develop improved cultivars with IRD tolerance. The continued success of the Illinois, USA horseradish industry depends on the breeding program to provide growers with new selections having increased vigor, outstanding root quality, high yields and IRD tolerance.
\end{abstract}

Keywords: Armoracia rusticana; Breeding; Fusarium; Variety development; Verticillium

\section{Introduction}

Horseradish (Armoracia rusticana Gaertn., Mey. \& Scherb.) is a hardy perennial that is member of the Brassicaceae family, and grown for its white, fleshy, and pungent roots, that are often used as condiment $[1,2]$. Horseradish is produced primarily in the United States and Europe, although there is production in other countries to some extent including Canada, China, and South Africa. Annually, about 1,600ha of horseradish are produced in the United States, with Illinois being the largest producer with about 800 ha $[1,2]$. The area just east of St. Louis, Missouri, USA (including Caseyville, Collinsville, and Edwardsville, Illinois) is considered the most concentrated horseradish production region in the world. Horseradish is a high value cash crop with the fresh product exceeding $\$ 20,000$ per ha in Illinois, USA [2]. Horseradish is also produced in several European countries including Austria, Czech Republic, Germany, Hungary, Poland, and Slovakia with about 3,000ha in total production.

Root diseases are a major hindrance to horseradish producers throughout the world. Root diseases typically cause greater problems for horseradish growers than foliar diseases, since 
diseases that affect roots have a direct influence on marketability and revenues generated. In most horseradish-growing areas in North America and Europe, internal root discoloration (IRD) is probably the most important disease of horseradish [2,3]. Although Verticillium dahlia was reported as the primary causal agent of IRD of horseradish roots in Illinois, USA [4], this disease in horseradish was later found to be caused by at least five fungi: $V$. dahlia, $V$. longisporum, and F. solani [3], and F. oxysporum and F. commune [5]. The discoloration caused by this disease complex often appears as streaks in the vascular tissue when the root is sectioned lengthwise or as black specks when the root is cross-sectioned [2]. The pathogens that cause IRD do not generally reduce overall yield productivity but will significantly reduce marketable yield due to blackening of roots (Figure 1).

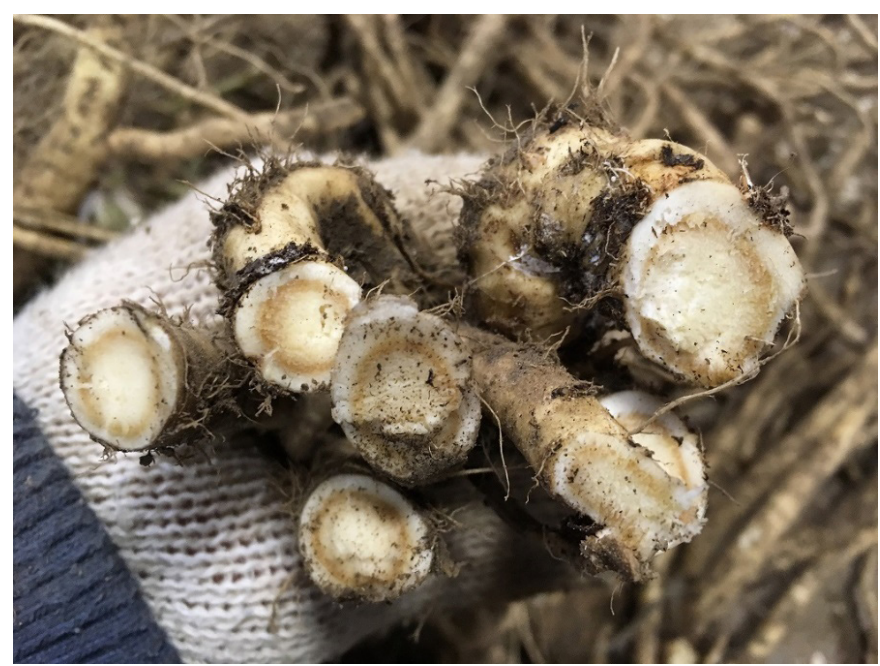

Figure 1: Horseradish roots with severe symptoms of internal discoloration in vascular tissues (Photo credit: Dr. S Alan Walters, 2017).

Internal root discoloration is a major production issue that is difficult to manage in horseradish production $[3,6]$. Horseradish yield losses up to $100 \%$ from IRD have been known to occur in Illinois, USA [3]. These pathogens that cause IRD can survive in infested fields for many years and will then germinate in the presence of host plant roots when environmental conditions are favorable. Plants in the Brassicaceae and some in the Solanaceae are susceptible hosts of the pathogens that cause IRD of horseradish roots [7]. In Illinois, USA, horseradish growers have had difficulty managing this disease complex. Although the use of crop rotation to non-susceptible hosts, especially maize (Zea mays) and soybean (Glycine max), is generally used by growers to reduce soil inoculum levels [2], previous attempts to control this disease by reducing soil inoculum densities through crop rotation were not successful due to the pathogens' large host range and ability to survive for long periods of time in the absence of susceptible hosts [8]. Since horseradish is a perennial, volunteer horseradish emerging in rotational crops can serve as a host for the pathogens that cause internal root discoloration, and elimination of volunteer horseradish may reduce soil inoculum levels of pathogens for subsequent horseradish production [9]. In further attempts to manage this disease, tissue culture is being used to develop clean horseradish planting stock, so that disease-free roots are being planted into fields, instead of using roots grown in infested soils which can perpetuate the IRD problem (2). Additionally, an active breeding program in Illinois, USA, is being used to develop horseradish clones with improved tolerance to the IRD disease complex.

The development of new, improved horseradish cultivars has been limited throughout the world [1]. Although horseradish plants flower profusely, fertility is low, which has been an impediment to the development of new cultivars using traditional breeding methods $[1,10,11]$. Before breeding efforts began in the USA in the 1950s, horseradish clones grown commercially were just superior, desirable clones selected from feral populations [10]. Even today, there is a special interest to assess and maintain local horseradish landraces, since it is a clonally propagated crop [12]. In Illinois, USA, the goal of the Illinois horseradish breeding program is to develop commercially acceptable horseradish cultivars with increased IRD tolerance while also providing high quality and high yielding roots through traditional breeding of Armoracia rusticana clones [1]. Therefore, the purpose of this study was twofold, first to evaluate current commercially grown horseradish cultivars for their tolerance to IRD under field conditions, and then to determine the suitability of specific cultivars in developing new improved cultivars with IRD tolerance.

\section{Materials and Methods}

\section{Internal root discoloration in horseradish cultivars}

Field experiments were set up at an Illinois horseradish grower location near Collinsville, Illinois, USA to evaluate the tolerance of ten commercial horseradish cultivars (15K, 315, 1038, 1573, $1590,1722,7586,9705$, D18-E1, and D25-E2) to IRD over three growing seasons $(2006,2007$, and 2008). All fields used over the three growing seasons had history of internal discoloration of horseradish roots. For each year, the field experiment was set up as a randomized complete block design with three replications. Horseradish roots used in the field experiment were obtained from horseradish root stock displaying no visual symptoms of 
internal discoloration or any other root diseases. Roots from each horseradish clone $(1.3 \mathrm{~cm}$ diameter were selected, washed with tap water, and cut into $15 \mathrm{~cm}$ long segments (sets) and placed in cold storage $\left(4^{\circ} \mathrm{C}\right)$ until planted into the field. Fields were plowed forming slightly raised beds into which sets were planted during mid-May each year. Horseradish sets were planted $60 \mathrm{~cm}$ apart with rows spaced approximately $86 \mathrm{~cm}$ apart. Ten sets were planted into each plot that were $6 \mathrm{~m}$ in length.

During the growing season, weeds were controlled by cultivation and hand-weeding. Fields were not irrigated at any time during the three growing seasons, as adequate moisture was provided through timely rainfall events. Plants were dug using a one-row modified potato digger in late November each year once foliage had been killed by freezing temperatures. The large primary roots were sectioned and evaluated for IRD incidence (percentage of roots per plot with discoloration symptoms) and severity (percentage of root area with discoloration symptoms). The severity of root discoloration was rated on a 0 to 9 scale: $0=$ no symptoms, $1-3=$ low (trace to $<25 \%) ; 4-6=$ moderate $(25 \%$ to $<50 \%)$; and $7-9=$ high ( $>50 \%$ ). Ratings were focused on the development of small black spots or a general darkening in the vascular and cortical root tissues.

\section{Breeding horseradish for improved IRD resistance}

Horseradish cultivars are highly heterozygous clones, and the only way to maintain a particular selection is though asexual propagation using root cuttings [1]. Cross pollinations are made among horseradish clones each year to develop seed as the initial step in the development of new and improved cultivars for the Illinois, USA horseradish industry. Many cross pollinations made in past years have involved cultivars that were evaluated in the IRD tolerance study. Therefore, horseradish crosses involving several of these cultivars were followed from field seedling stage through multiple years of field selection until final selections were made for new cultivars having IRD tolerance. Seedlings were developed from specific crosses or open pollination (OP) of horseradish cultivars having unknown pollen sources. Specific horseradish cultivar crosses (listed in parentheses) were first planted as seedlings in 2007 (D25-E2 OP, 1038 OP, 1573 OP, 1590 OP, 7586 OP), 2008 (1590 OP, 15K OP, and 1038 OP), 2009 (15K OP, 315 OP, 1573 OP, 1590 OP, 315x15K), and 2010 (315 OP, 7586 OP), and followed through the horseradish breeding field selection process in subsequent years to determine their effectiveness in producing new IRD tolerant cultivars. Seedlings and later evaluations of a specific cross were primarily discarded due to visible internal discoloration symptoms that developed in roots. Methods of planting, harvesting, and root assessment were similar to the horseradish IRD cultivar evaluation experiment. The purpose of this study was to determine the effectiveness of horseradish cultivars as parents to provide improved clonal selections having IRD tolerance.

\section{Data analysis}

Data were first subjected to analysis of variance procedures using the general linear models procedure of SAS (version 9.4,
SAS Institute, Cary, NC, USA) for the IRD horseradish cultivar experiment, with horseradish cultivar and year interactions also evaluated. Fisher's protected least significant difference (LSD) test was used to separate horseradish cultivar means at $\mathrm{P} \leq 0.05$ for IRD incidence and severity. Student's $t$-test $(\mathrm{P} \leq 0.05)$ was used to assess differences between horseradish cultivars as parents (using sample points over years) to provide new clonal selections with IRD tolerance.

\section{Results and Discussion}

\section{Internal root discoloration in horseradish clones}

Data analysis indicated that the incidence and severity of IRD in horseradish roots were definitely influenced by cultivar (Table 1), but an interaction $(\mathrm{P} \leq 0.05)$ was detected between horseradish cultivar and year for IRD incidence and severity in roots; therefore, these data are shown by year. Most horseradish cultivars had consistent high IRD incidence in roots (>80\%) over the 3 years (Table 1). Horseradish clones having consistently high IRD incidence over the 3 growing seasons were 1722, 1573, 315, D18-E1, 1590, 1038 and D25-E2. Surveys of Illinois, USA horseradish growers in 2006 and 2007 indicated that the most widely grown cultivars at that time were $1590,15 \mathrm{~K}, 1573,7586$, D18-E1, D25-E2, 1038, 22C, 3038, and 9705 [13,14], with 1590, $1573,7586,1038$, and 1722 perceived by growers to have severe IRD problems [13]. Although many of these cultivars are still widely grown today, an outstanding new cultivar (315) was released in 2007, having good set formation, high biomass potential, smooth roots, with high amounts of IRD tolerance [15]. Currently, 315 is the most widely grown cultivar by the Illinois, USA, horseradish industry. However, most of the IRD susceptible cultivars evaluated in this study are still grown commercially today. Two horseradish cultivars had inconsistent IRD incidence responses over the three growing seasons. The cultivar 7586 had high incidence during the first two growing seasons and then only $63 \%$ incidence in the third year, while 9705 had only a high IRD incidence during the first year and lower observed IRD incidences at $63 \%$ and $70 \%$ during 2007 and 2008, respectively. Dorris et al. [13] indicated that 7586 and 9705 are perceived by growers to have less IRD problems than many other horseradish cultivars and appear similar to $15 \mathrm{~K}$ in their level of tolerance. However, in this study, only15K had IRD incidence consistently below $80 \%$, with observable symptom responses detected between 70 and $74 \%$ over the 3 growing seasons. Although $15 \mathrm{~K}$ has consistently shown field tolerance to IRD, it has problems of rough barky roots which are not preferred by the industry.

Most horseradish cultivars had moderate amounts of IRD severity symptoms in roots ( 4 to 6 on average, based on rating scale of 0 to 9 ) over the 3 years, and none had high amounts of severity (Table 1). Horseradish cultivars having consistent moderate amounts of IRD severity symptoms in roots over the three growing seasons were 1722, 1573, D18-E1, 1590, 1038 and D25-E2. All of these cultivars also had high IRD incidence in roots, indicating their high susceptibility to the IRD disease complex. Hamblin 
[16] evaluated several horseradish breeding lines in Illinois, USA, under infested IRD pathogen field conditions, and found that most had moderate amounts of IRD symptoms in roots, with only a few having limited disease development. In this study, four horseradish cultivars $(315,7586,9705$ and $15 \mathrm{~K})$ tended to have lower amounts of IRD symptom severity than those previously stated. Although 315 had high amounts of incidence over the three growing seasons (between $82 \%$ and $94 \%$ ), the IRD symptom severity in roots tended to be less compared to other cultivars that also had high IRD incidence. Over the three growing seasons, two cultivars, 7586 and 9705, had consistently lower IRD symptom severity in roots compared to all other cultivars, except $15 \mathrm{~K}$. Besides having the lowest IRD incidence in roots over the three growing seasons, $15 \mathrm{~K}$ also had the lowest IRD symptom severity in roots.

Table 1: Incidence and severity of internal root discoloration (IRD) symptoms in horseradish cultivars grown in commercial production fields near Collinsville, Illinois, USA, over 3 growing seasons.

\begin{tabular}{|c|c|c|c|c|c|c|}
\hline \multirow{2}{*}{$\begin{array}{c}\text { Horserad- } \\
\text { ish Clone }\end{array}$} & \multicolumn{2}{|c|}{ Season 1-2006 } & \multicolumn{2}{c|}{ Season 2-2007 } & \multicolumn{2}{c|}{ Season 3-2008 } \\
\cline { 2 - 7 } & IRD Incidence & IRD Symptom Severity & IRD Incidence & IRD Symptom Severity & IRD Incidence & $\begin{array}{c}\text { IRD Symptom Se- } \\
\text { verity }\end{array}$ \\
\hline 1722 & $96 \mathrm{~A}$ & $4.3 \mathrm{~A}$ & $94 \mathrm{AB}$ & $4.2 \mathrm{BC}$ & $95 \mathrm{~A}$ & $5.5 \mathrm{~A}$ \\
\hline 1573 & $96 \mathrm{~A}$ & $4.2 \mathrm{~A}$ & $100 \mathrm{~A}$ & $4.5 \mathrm{BC}$ & $92 \mathrm{AB}$ & $4.9 \mathrm{~A}$ \\
\hline $\mathrm{D} 18-\mathrm{E} 1$ & $90 \mathrm{~A}$ & $4.1 \mathrm{~A}$ & $100 \mathrm{~A}$ & $4.5 \mathrm{BC}$ & $94 \mathrm{~A}$ & $4.2 \mathrm{~A}$ \\
\hline $\mathrm{D} 25-\mathrm{E} 2$ & $87 \mathrm{~A}$ & $4.3 \mathrm{~A}$ & $100 \mathrm{~A}$ & $5.4 \mathrm{~A}$ & $98 \mathrm{~A}$ & $4.9 \mathrm{~A}$ \\
\hline 315 & $83 \mathrm{AB}$ & $3.5 \mathrm{AB}$ & $83 \mathrm{BC}$ & $3.8 \mathrm{C}$ & $32 \mathrm{~B}$ & $2.6 \mathrm{~B}$ \\
\hline 1038 & $83 \mathrm{AB}$ & $4.1 \mathrm{~A}$ & $93 \mathrm{AB}$ & $5.0 \mathrm{AB}$ & $90 \mathrm{AB}$ & $4.2 \mathrm{~A}$ \\
\hline 1590 & $83 \mathrm{AB}$ & $4.0 \mathrm{~A}$ & $100 \mathrm{~A}$ & $5.7 \mathrm{~A}$ & $96 \mathrm{~A}$ & $4.7 \mathrm{~A}$ \\
\hline 7586 & $83 \mathrm{AB}$ & $3.0 \mathrm{BC}$ & $83 \mathrm{BC}$ & $2.3 \mathrm{D}$ & $63 \mathrm{C}$ & $1.6 \mathrm{~B}$ \\
\hline 9705 & $83 \mathrm{AB}$ & $3.0 \mathrm{BC}$ & $63 \mathrm{D}$ & $1.0 \mathrm{E}$ & $70 \mathrm{C}$ & $2.3 \mathrm{~B}$ \\
\hline $15 \mathrm{~K}$ & $74 \mathrm{~B}$ & $2.3 \mathrm{C}$ & $72 \mathrm{CD}$ & $1.0 \mathrm{E}$ & $2.3 \mathrm{~B}$ & $70 \mathrm{C}$ \\
\hline
\end{tabular}

IRD incidence is the percentage of roots with visible IRD symptoms.

IRD symptom severity was rated: 0 is no discoloration, 1-3 is low amounts of root discoloration, 4 to 6 is moderate amounts of root discoloration, and 7 to 9 is high amounts of root discoloration.

Horseradish clones ranked according to IRD incidence in Season 1-2006.

These results indicate that $15 \mathrm{~K}$ consistently provided high IRD tolerance which would most likely provide improved marketable yields in soils infested with IRD pathogens due to less roots with visible IRD symptoms. These results indicate that most horseradish cultivars evaluated were highly susceptible to the IRD disease complex, with only $15 \mathrm{~K}$ having consistent field tolerance. This cultivar has previously been observed under commercial field conditions by the author to have some tolerance to IRD. Other horseradish cultivars that may have some potential IRD tolerance under field conditions are 315, 7586, 9705, based on the IRD incidence and/or IRD symptom severity that developed in roots. The horseradish cultivar 315 is an open-pollinated selection from 7586 (pollen from unknown source) and may have some tolerance inherited from the female parent. Horseradish cultivar assessments in IRD pathogen infested fields provide the basis for determining susceptible or tolerance responses and allow the most effective choice of cultivars that would have the greatest potential for increased root marketability. Moreover, results indicated that over all three years IRD incidence and symptom severity development in roots were highly correlated $\left(\mathrm{r}^{2}=0.636, \mathrm{P}=0.0001\right)$. This indicates that horseradish cultivars displaying high incidence of internal discoloration in roots would also generally have higher amounts of severity symptoms, compared to those with lower incidence.

\section{Breeding horseradish for improved IRD resistance}

Most horseradish cultivars evaluated as parents were ineffective at providing IRD tolerant offspring (Table 2). Horseradish cultivars, D25-E2, 1038, 1573, and 1590 that were highly susceptible to IRD under field conditions (Table 1), produced no IRD tolerant offspring from 3,020 seedlings evaluated under field conditions. Another cultivar, 7586, that was shown to have some potential IRD tolerance under field conditions, produced no tolerant offspring from 210 seedlings evaluated in infested field soils. However, two cultivars evaluated did show potential as parents to produce IRD tolerant offspring (Table 2). As parents, both 315 and $15 \mathrm{~K}$ produced more new IRD tolerant cultivars compared to all other horseradish cultivars evaluated. Additionally, these two cultivars did not differ $(\mathrm{P}>0.05)$ from each other for the ability to produce new IRD tolerant cultivars. Therefore, both $15 \mathrm{~K}$ and 315 would be excellent choices to use in a breeding program to develop new IRD tolerant horseradish cultivars. Moreover, when genetics of both $15 \mathrm{~K}$ and 315 were combined together, less seedling evaluations were required to produce new IRD tolerant cultivars.

The results of this study demonstrated that some horseradish cultivars are definitely better suited as parents to produce new cultivars with IRD tolerance. Both 315 and 15K appear to have superior genetics for developing new and improved IRD tolerant 
offspring. The horseradish cultivar $15 \mathrm{~K}$ is completely selfincompatible and would be a good choice as a female parent since no emasculation would be require when delivering pollen from another clonal selection to its flowers when making hand-crosses [11]. In comparison, 315 is partially self-compatible and would require emasculation, when used as a female parent; thus, 315 would probably be better utilized as a male pollen donor on another self-incompatible clone. This indicates that parent selection, as well as understanding horseradish clonal compatibility, are both important when attempting to develop new horseradish cultivars with improved IRD tolerance. The current overall goal of the Illinois, USA, horseradish breeding program is to develop commercially acceptable horseradish cultivars with increased IRD tolerance along with high quality and high-yielding roots through traditional breeding [1].

Table 2: Horseradish cultivars used in crosses for development of new cultivars having internal root discoloration (IRD) tolerance, with number of seedlings evaluated for specific crosses and eventual new IRD tolerant cultivars resulting from those crosses.

\begin{tabular}{|c|c|c|c|}
\hline Year and Specific Horseradish Cross & $\begin{array}{c}\text { Number Seedlings Eval- } \\
\text { uated }\end{array}$ & $\begin{array}{l}\text { New Horseradish Cultivars Released } \\
\text { with IRD Tolerance (after 4-5 years } \\
\text { of field evaluations) }\end{array}$ & $\begin{array}{c}\text { Percentage of New IRD Tolerant } \\
\text { Horseradish Cultivars Obtained } \\
\text { from Cross }\end{array}$ \\
\hline \multicolumn{4}{|c|}{2007 Seedlings } \\
\hline D25-E2 OP & 250 & 0 & 0 \\
\hline $1038 \mathrm{OP}$ & 200 & 0 & 0 \\
\hline $1573 \mathrm{OP}$ & 300 & 0 & 0 \\
\hline $1590 \mathrm{OP}$ & 1500 & 0 & 0 \\
\hline 7586 OP & 125 & 0 & 0 \\
\hline \multicolumn{4}{|c|}{2008 Seedlings } \\
\hline 1590 OP & 215 & 0 & 0 \\
\hline $1038 \mathrm{OP}$ & 245 & 0 & 0 \\
\hline $15 \mathrm{~K} \mathrm{OP}$ & 250 & 1 & $<1$ \\
\hline \multicolumn{4}{|c|}{2009 Seedlings } \\
\hline $15 \mathrm{~K} \mathrm{OP}$ & 200 & 1 & $<1$ \\
\hline 315 OP & 150 & 1 & $<1$ \\
\hline $1573 \mathrm{OP}$ & 225 & 0 & 0 \\
\hline $1590 \mathrm{OP}$ & 85 & 0 & 0 \\
\hline $315 \times 15 K$ & 25 & 1 & 4 \\
\hline \multicolumn{4}{|c|}{2010 Seedlings } \\
\hline 315 OP & 250 & 1 & $<1$ \\
\hline $7586 \mathrm{OP}$ & 85 & 0 & 0 \\
\hline $\begin{array}{l}\text { Student's t-test comparing } 15 \mathrm{~K} \text { to } \\
\text { D25E2, 1038, 1573, 1590, and } 7586 \\
\text { as parents for developing new IRD } \\
\text { tolerant cultivars }\end{array}$ & - & $P=0.0001$ & $P=0.0001$ \\
\hline $\begin{array}{l}\text { Student's t-test comparing } 315 \text { to } \\
\text { D25E2, 1038, 1573, 1590, and } 7586 \\
\text { as parents for developing new IRD } \\
\text { tolerant cultivars }\end{array}$ & - & $P=0.0001$ & $P=0.0001$ \\
\hline $\begin{array}{l}\text { Student's t-test comparing } 15 \mathrm{~K} \text { and } \\
315 \text { as parents for developing new IRD } \\
\text { tolerant cultivars }\end{array}$ & - & NS & NS \\
\hline
\end{tabular}

OP is open-pollinated, with only female parent known.

Student's t-test was used to assess differences among horseradish cultivars as parents for the likelihood of producing new IRD tolerant cultivars. 


\section{Summary}

Internal root discoloration of horseradish roots occur throughout the world where this crop is grown and is often times the primary limiting factor in horseradish production [3,4]. This study demonstrated that most commercial horseradish cultivars grown in Illinois, USA have no field tolerance to IRD, and of the few that do, two clones (15K and 315) were shown to be effective parents for developing new cultivars with IRD tolerance. Breeding for tolerance to this disease complex has been the major focus in new cultivar development in Illinois USA for the last several decades. Significant progress has been made in recent years in developing IRD tolerant horseradish cultivars with improved root yield and quality characteristics, but many cultivars grown still lack tolerance. The lack of IRD tolerance in many horseradish cultivars often creates a significant problem for the Illinois, USA industry, especially in those years in which IRD is highly prevalent. Often times, susceptible cultivars are preferred over others due to their high yields, or exceptional quality characteristics. For example, 1573 is often grown for its high production potential, while 9705 is grown for its smooth, high quality roots. In these cases, the cultivars will tend to be grown in fields with a minimal history of IRD, to minimize the development of root discoloration; but sometimes, these cultivars develop IRD symptoms so severe that entire horseradish fields are disced and plowed, due to low marketable root yields. Both $15 \mathrm{~K}$ and 315 are excellent horseradish cultivars to use in a breeding program to develop new IRD tolerant clonal selections, due to their IRD tolerance. Although these two cultivars have been used in the Illinois, USA horseradish breeding program, other germplasm materials identified as tolerant by the author to IRD, as well as those identified by Atibalentja and Eastburn [17] as resistant to $V$. dahlia, are being used as materials to develop future IRD tolerant cultivars. Although new IRD tolerant horseradish cultivars have been released from the Illinois, USA horseradish breeding program in recent years by the author, it takes several years for growers to increase root cuttings through vegetative propagation to reach the amounts required for commercial production, and many of the new horseradish selections released to growers over the last decade are just now at the point of being commercially grown. The continued success of the Illinois, USA horseradish industry really depends on the breeding program for continued development of new selections having IRD field tolerance.

\section{Acknowledgement}

Horseradish Growers of Illinois, USA.

\section{References}

1. Shehata A, Mulwa R, Babadoost MS, Uchanski M, Norton MA, et al. (2009) Horseradish: botany, horticulture, breeding. Hortic Rev 35: 221-262.

2. Walters SA, Wahle EA (2010) Horseradish production in Illinois. Hort Technology 20(2): 267-276.

3. Babadoost M, Chen W, Bratsch AD, Eastman CE (2004) Verticillium longisporum and Fusarium solani: two new species in the complex of internal discoloration of horseradish roots. Plant Pathol 53(5): 669-676.

4. Eastburn DM, Chang RJ (1994) Verticillium dahliae: a causal agent of root discoloration of horseradish in Illinois. Plant Dis 78(5): 496-498.

5. Yu, JM, Babadoost M (2013) Occurrence of Fusarium commune and F. oxysporum in horseradish roots. Plant Dis 97(4): 453-460.

6. Babadoost M (2006) Development of internal discoloration of horseradish root in commercial fields. In: Wahle EA (Ed.), Horseradish Research Review \& Proc Horseradish Growers School, University of Illinois Extension, Edwardsville, USA, pp. 1-2.

7. Chang RJ, Eastburn DM (1994) Host range of Verticillium dahliae from horseradish and pathogenicity of strains. Plant Dis 78(5): 503-506.

8. Khan A, Atibalentja N, Eastburn DM (2000) Influence of inoculum density of Verticillium dahlia on root discoloration of horseradish. Plant Dis 84(3): 309-315.

9. Rundle MF, Walters SA, Young BG (2007) Efficacy of corn and soybean herbicides on volunteer horseradish (Armoracia rusticana). Weed Technol 21: 501-505.

10. Rhodes AM, Courter JW, Shurtleff MC, Vandemark JS (1965) Improving horseradish through breeding. Illinois Res 7(4): 17.

11. Walters SA, Bernhardt P, Joseph M, Miller AJ (2016) Pollination and sterility in horseradish. Plant Breeding 135(6): 735-742.

12. Agneta R, Möllers C, De Maria S, Rivelli, AR (2014) Evaluation of root yield traits and glucosinolate concentration of different Armoracia rusticana accessions in Basilicata region (southern Italy). Scientia Horticulturae 170(7): 249-255.

13. Dorris F, Walters, SA, Wahle EA (2007) Horseradish variety survey: 2006. In Wahle EA (Ed.), Horseradish Res Rev \& Proc Horseradish Growers School, Univ Illinois Extension, Edwardsville, USA, pp. 11-13.

14. Dorris F, Walters SA, Wahle EA (2008) Horseradish variety survey: 2007. In Wahle EA (Ed.), Horseradish Res Rev \& Proc Horseradish Growers School, Univ Illinois Extension, Edwardsville, USA, pp. 18-21.

15. Walters SA (2007) Horseradish Breeding at Southern Illinois University for 2006. In Wahle EA (Ed.), Horseradish Res Rev \& Proc Horseradish Growers School, Univ Illinois Extension, Edwardsville, USA, pp. 5-7.

16. Hamblin AM (2001) Disease reaction of various horseradish selections and crosses to root rot 2000. Plant Dis Manag Rep 16: 91.

17. Atibalentja N, Eastburn DM (1998) Verticillium dahlia resistance in horseradish germplasm from the University of Illinois collection. Plant Dis 82(2): 176-180.

For possible submissions Click below: 